\title{
Magnetic Behaviour of Perovskite Compositions Derived from $\mathrm{BiFeO}_{3}$
}

\author{
Andrei N. Salak ${ }^{1, * \mathbb{D}}$, João Pedro V. Cardoso ${ }^{1}$, Joaquim M. Vieira ${ }^{1}$, Vladimir V. Shvartsman ${ }^{2}$ (D), \\ Dmitry D. Khalyavin ${ }^{3}$, Elena L. Fertman ${ }^{4} \mathbb{D}$, Alexey V. Fedorchenko ${ }^{(\mathbb{D}}$, Anatoli V. Pushkarev ${ }^{5}$ (D), \\ Yury V. Radyush ${ }^{5}$, Nikolai M. Olekhnovich ${ }^{5}$, Róbert Tarasenko ${ }^{6}$, Alexander Feher ${ }^{6}$ and Erik Čižmár ${ }^{6, *}$ (D)
}

Citation: Salak, A.N.; Cardoso, J.P.V.; Vieira, J.M.; Shvartsman, V.V.; Khalyavin, D.D.; Fertman, E.L.; Fedorchenko, A.V.; Pushkarev, A.V.; Radyush, Y.V.; Olekhnovich, N.M.; et al. Magnetic Behaviour of Perovskite Compositions Derived from $\mathrm{BiFeO}_{3}$. Magnetochemistry 2021, 7, 151. https://doi.org/10.3390/ magnetochemistry7110151

Academic Editors: Masami Tsubota and Jiro Kitagawa

Received: 5 October 2021

Accepted: 14 November 2021

Published: 16 November 2021

Publisher's Note: MDPI stays neutral with regard to jurisdictional claims in published maps and institutional affiliations.

Copyright: (c) 2021 by the authors. Licensee MDPI, Basel, Switzerland. This article is an open access article distributed under the terms and conditions of the Creative Commons Attribution (CC BY) license (https:/ / creativecommons.org/licenses/by/ $4.0 /)$.
1 Department of Materials and Ceramics Engineering/CICECO-Aveiro Institute of Materials, University of Aveiro, 3810-193 Aveiro, Portugal; joaopcardoso@ua.pt (J.P.V.C.); jvieira@ua.pt (J.M.V.)

2 Institute for Materials Science and CENIDE-Center for Nanointegration Duisburg-Essen, University of Duisburg-Essen, 45141 Essen, Germany; vladimir.shvartsman@uni-due.de

3 ISIS Facility, Rutherford Appleton Laboratory, Chilton, Didcot, Oxfordshire OX11 0QX, UK; dmitry.khalyavin@stfc.ac.uk

4 B. Verkin Institute for Low Temperature Physics and Engineering, National Academy of Sciences of Ukraine, Nauky 47, 61103 Kharkiv, Ukraine; fertman@ilt.kharkov.ua (E.L.F.); fedorchenko.alexey@gmail.com (A.V.F.)

5 Scientific-Practical Materials Research Centre, National Academy of Sciences of Belarus, P. Brovka 19, 220072 Minsk, Belarus; pushk@physics.by (A.V.P.); radyush@ifttp.bas-net.by (Y.V.R.); olekhnov@ifttp.bas-net.by (N.M.O.)

6 Institute of Physics, Faculty of Science, Pavol Jozef Šafárik University, Park Angelinum 9, 04154 Košice, Slovakia; robert.tarasenko@upjs.sk (R.T.); alexander.feher@upjs.sk (A.F.)

* Correspondence: salak@ua.pt (A.N.S.); erik.cizmar@upjs.sk (E.Č.)

Abstract: The phase content and sequence, the crystal structure, and the magnetic properties of perovskite solid solutions of the $(1-y) \mathrm{BiFeO}_{3}-y \mathrm{BiZn}_{0.5} \mathrm{Ti}_{0.5} \mathrm{O}_{3}$ series $(0.05 \leq y \leq 0.90)$ synthesized under high pressure have been studied. Two perovskite phases, namely the rhombohedral $R 3 c$ and the tetragonal $P 4 \mathrm{~mm}$, which correspond to the structural types of the end members, $\mathrm{BiFeO}_{3}$ and $\mathrm{BiZn}_{0.5} \mathrm{Ti}_{0.5} \mathrm{O}_{3}$, respectively, were revealed in the as-synthesized samples. The rhombohedral and the tetragonal phases were found to coexist in the compositional range of $0.30 \leq y \leq 0.90$. Magnetic properties of the $\mathrm{BiFe}_{1-y}\left[\mathrm{Zn}_{0.5} \mathrm{Ti}_{0.5}\right]_{y} \mathrm{O}_{3}$ ceramics with $y<0.30$ were measured as a function of temperature. The obtained compositional variations of the normalized unit-cell volume and the Néel temperature of the $\mathrm{BiFe}_{1-y}\left[\mathrm{Zn}_{0.5} \mathrm{Ti}_{0.5}\right]_{y} \mathrm{O}_{3}$ perovskites in the range of their rhombohedral phase were compared with the respective dependences for the $\mathrm{BiFe}_{1-y} B^{3+}{ }_{y} \mathrm{O}_{3}$ perovskites (where $B^{3+}=\mathrm{Ga}$, $\mathrm{Co}, \mathrm{Mn}, \mathrm{Cr}$, and $\mathrm{Sc}$ ). The role of the high-pressure synthesis in the formation of the antiferromagnetic states different from the modulated cycloidal one characteristic of the parent $\mathrm{BiFeO}_{3}$ is discussed.

Keywords: atomic substitution; Néel temperature; G-type antiferromagnetic; weak ferromagnetism; collinear magnetic ground state

\section{Introduction}

Bismuth ferrite is one of few type-I multiferroics, namely those solids in which the coexisting (anti)ferroelectric order and the (anti)ferromagnetic order are caused by independent mechanisms [1]. Ferroelectricity in $\mathrm{BiFeO}_{3}$ is induced by the electronic instability of the lone-pair $\mathrm{Bi}^{3+}$ cations, while the antiferromagnetism in this material with the Néel temperature, $T_{\mathrm{N}}$, as high as $643 \mathrm{~K}$ results from the superexchange interactions between $\mathrm{Fe}^{3+}$ cations [2]. Besides, the distorted crystal structure of this perovskite, involving large polar atomic displacements and octahedral tilting, gives rise to competing antisymmetric Dzyaloshinskii-Moriya (DM) interactions [3]. The part of antisymmetric exchange associated with the polar distortions favours a spatially modulated ground state in the form of a long-period incommensurate cycloid. Contrary, the antisymmetric exchange imposed by the octahedral tilting requires a non-modulated canted weak ferromagnetic (FM) state. In 
the undoped $\mathrm{BiFeO}_{3}$, the former contribution wins promoting the long-period modulated spin ordering that averages the net magnetization to zero [4]. This modulation, however, can be suppressed via chemical modification or thin-film strain engineering, resulting in a state where both the ferroelectric polarization and spontaneous magnetization coexist.

The bismuth site substitutions in $\mathrm{BiFeO}_{3}$ are the most studied. The compositional dependent structural transitions and variations of the magnetic ordering of the $\mathrm{Bi}_{1-x} A^{3+}{ }_{x} \mathrm{FeO}_{3}$ perovskites series $(0 \leq x<1)$ have been revealed [5-8]. In particular, the minimum substitution rates for rare earth cations sufficient to destroy the cycloidal modulation were estimated [9]. Besides, the correlations between the size of the substituting cation and the transition temperature were found $[5,10]$.

Chemical modifications in the iron site of $\mathrm{BiFeO}_{3}$ appear to be the direct approach to tune the magnetic behaviour of this material. However, using the conventional synthesis routes, it is possible to achieve the substitution rates of a few at.\% only. Most of the reported single-phase $\mathrm{BiFe}_{1-y} B^{3+}{ }_{y} \mathrm{O}_{3}$ perovskite compositions with $x>0.10$ were prepared using the high-pressure synthesis technique [11-21]. The only exception appears to be the $\mathrm{BiFe}_{1-y} \mathrm{Mn}_{y} \mathrm{O}_{3}$ system, in which up to about 30 at.\% of the iron-to-manganese substitution is possible via the conventional ceramic route [22]. It should be noticed here that the $B$-site substituted compositions derived from bismuth ferrite using the conventional route belong to the same space group, $R 3 c$, as that of the parent $\mathrm{BiFeO}_{3}$, while high-pressure synthesis can result in the formation of other structural phases. For instance, the same perovskite composition, $\mathrm{BiFe}_{0.75} \mathrm{Mn}_{0.25} \mathrm{O}_{3}$, prepared by solid-state synthesis at ambient pressure or via high-pressure synthesis is rhombohedral or orthorhombic, respectively [22]. The full-range range substitutions of $\mathrm{Fe}^{3+}$ with trivalent cations whose ionic radii are considerably smaller (gallium [16]) or considerably larger (scandium [19]) than the iron one were successfully performed using high-pressure synthesis. In high-pressure stabilized perovskite solid solutions of the $\mathrm{BiFe}_{1-y} \mathrm{Sc}_{y} \mathrm{O}_{3}$ system a series of structural transitions with increasing $y$ was found. Moreover, it was revealed that annealing the as-prepared $\mathrm{BiFe}_{1-y} \mathrm{Sc}_{y} \mathrm{O}_{3}$ perovskites $(y \geq 0.3)$ results in irreversible transformations into new perovskite phases with interesting combinations of ferroic orders [23]. It was demonstrated that the observed effect is a manifestation of conversion polymorphism, which is a general phenomenon in the high-pressure stabilized oxygen-octahedral structural phases [23]. Structure, dielectric response, and magnetic behaviour of the as-prepared and the converted polymorphs of the (1-y) $\mathrm{BiFeO}_{3}-y \mathrm{BiScO}_{3}$ perovskites have been considered in great detail [24-27]. Magnetic ordering was detected in the $\mathrm{BiFe}_{1-y} \mathrm{Sc}_{y} \mathrm{O}_{3}$ compositions with up to 60 at.\% of scandium with a near-linear $T_{\mathrm{N}}(y)$ dependence. In the $0.1 \leq y<0.3$ range of this solid solution system, some peculiarities of the temperature-dependent magnetic moment below $T_{\mathrm{N}}$ were observed and associated with possible transitions between three different antiferromagnetic (AFM) structures, namely those corresponding to collinear, canted, and cycloidal spin arrangements [26]. Similar temperature anomalies of the magnetic behaviour below $T_{\mathrm{N}}$ were then revealed in the Fe-rich compositional range of the $\mathrm{BiFe}_{1-y}\left[\mathrm{Zn}_{0.5} \mathrm{Ti}_{0.5}\right]_{y} \mathrm{O}_{3}$ perovskites phases prepared using high-pressure synthesis [28]. The (1-y) $\mathrm{BiFeO}_{3}-y \mathrm{BiZn}_{0.5} \mathrm{Ti}_{0.5} \mathrm{O}_{3}$ series is of interest as the promising lead-free system in which the compositional range of coexistence of two polar phases (the morphotropic phase boundary/region, MPB) occurs.

Although a number of the $\mathrm{BiFe}_{1-y} B^{3+}{ }_{y} \mathrm{O}_{3}$ perovskite series has already been prepared and characterized [11-21,28,29], to the best of our knowledge, the obtained structural and magnetic data have not been generalized in respect of the ionic size of the substituting cation. This is certainly worthy of consideration as the comparative studies of the variation of structural characteristics and transition temperatures in solid solutions and series the isomorphous substitutions of are known to be very convenient to understand some features and predict properties of new compositions [30].

In this paper, we considered the compositional behaviours of the crystal structure and the magnetic properties of the $\mathrm{BiFe}_{1-y}\left[\mathrm{Zn}_{0.5} \mathrm{Ti}_{0.5}\right]_{y} \mathrm{O}_{3}$ perovskite phases and compared them with the respective dependences of $\mathrm{BiFe}_{1-y} B^{3+}{ }_{y} \mathrm{O}_{3}$ perovskites (where $B^{3+}=\mathrm{Ga}$, $\mathrm{Co}, \mathrm{Mn}, \mathrm{Cr}$, and Sc) in the vicinity of parent bismuth ferrite. Among these, $\mathrm{Cr}^{3+}, \mathrm{Mn}^{3+}$, 
and $\mathrm{Co}^{3+}$ are magnetic cations of transition metals from the same $3 d$ series to which iron belongs, while $\mathrm{Ga}^{3+}, \mathrm{Sc}^{3+}$ and $\left[\mathrm{Zn}_{0.5} \mathrm{Ti}_{0.5}\right]^{3+}$ are non-magnetic. Besides, as compared with iron, $\mathrm{Ga}^{3+}$ is smaller, $\mathrm{Sc}^{3+}$ is considerably bigger, and $\left[\mathrm{Zn}_{0.5} \mathrm{Ti}_{0.5}\right]^{3+}$ is slightly bigger than $\mathrm{Fe}^{3+}$ in octahedral coordination. Although no simple model based on microscopic magneto-structural correlations can be applied and predicting the behaviour of the doped perovskites requires extensive DFT calculations that include detailed information about the structural modifications [7], the compared cases appear to be various enough to conclude on possible correlations and trends.

\section{Results}

Analysis of the XRD data of the as-synthesized (unannealed) samples of the $(1-y) \mathrm{BiFeO}_{3}-$ $y \mathrm{BiZn}_{0.5} \mathrm{Ti}_{0.5} \mathrm{O}_{3}$ series has revealed no crystalline phase apart from the perovskite ones. It was found from the comparison of the XRD patterns of the compositions with increasing $y$ that the samples with $y<0.30$ are single-phase perovskites with the rhombohedral $R 3 c$ structure. An increase of the $\mathrm{Zn}$-Ti content results in the appearance and growth of new diffraction peaks (Figure 1). These peaks were associated with the tetragonal perovskite phase similar to that of the parent $\mathrm{BiZn}_{0.5} \mathrm{Ti}_{0.5} \mathrm{O}_{3}$ [31]. In the range of $0.30 \leq y \leq 0.90$, the rhombohedral and the tetragonal phases coexist. These two were the only phases detected in the whole compositional range, and no other perovskite phase has been revealed. This is in contradiction with the results of Pan et al. [18]) who observed an intermediate monoclinic phase in $\mathrm{BiFe}_{1-y}\left[\mathrm{Zn}_{0.5} \mathrm{Ti}_{0.5}\right]_{y} \mathrm{O}_{3}$ between $y=0.40$ and 0.50 . It should be noted, however, that Pan et al. studied the annealed samples while no thermal treatment was performed in this work. As mentioned in the Introduction, annealing of the high-pressure stabilized materials can lead to irreversible polymorph transformations [23].

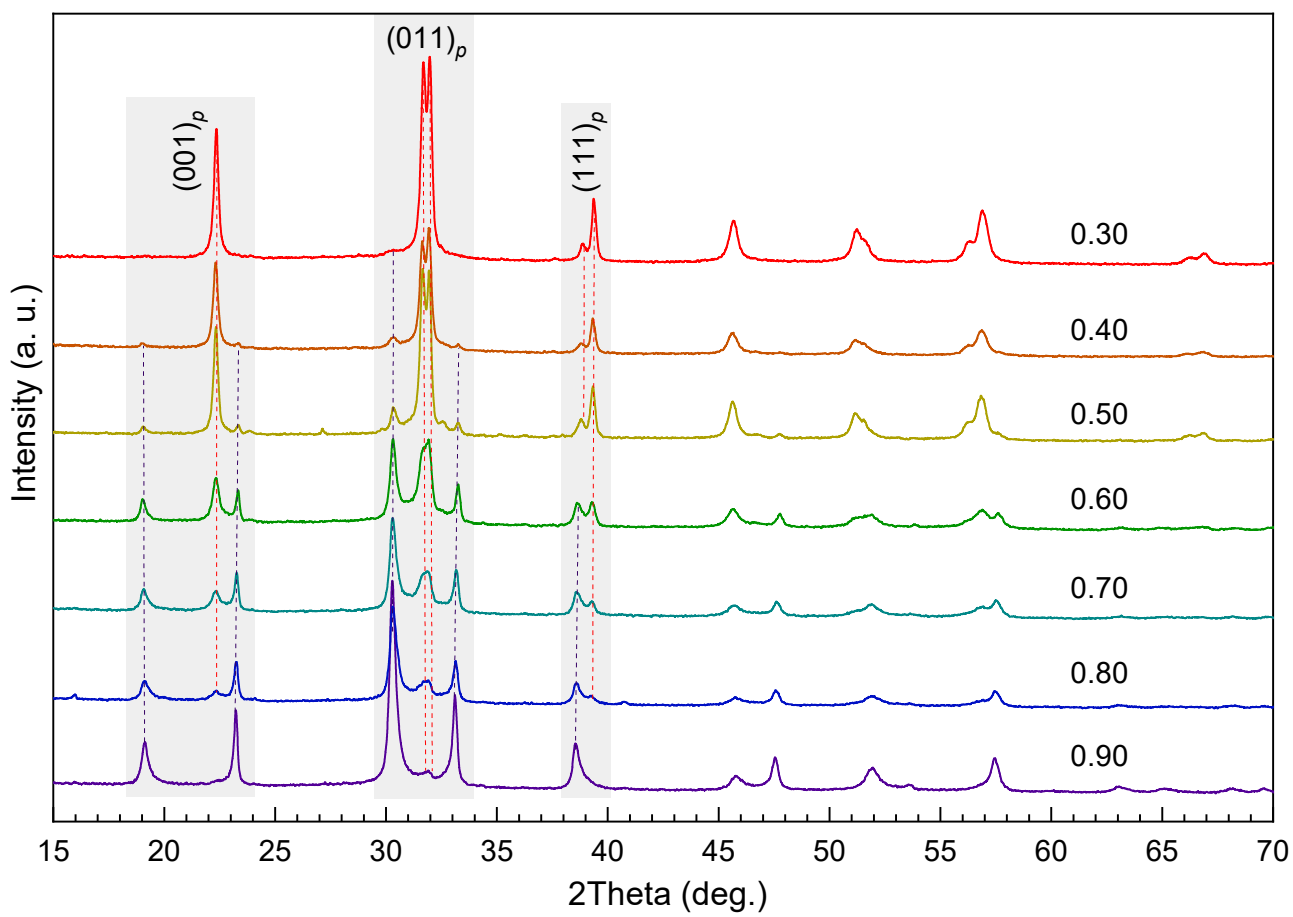

Figure 1. The XRD patterns of the $(1-y) \mathrm{BiFeO}_{3}-y \mathrm{BiZn}_{0.5} \mathrm{Ti}_{0.5} \mathrm{O}_{3}$ samples as-synthesized under high pressure. The numbers at the diffractograms denote the $y$ values. The shadow areas indicate the angular ranges of $(001)_{p},(011)_{p}$ and $(111)_{p}$ reflection families of the primitive perovskite lattice. The dotted lines point out the 2Theta positions of the reflections corresponding to the rhombohedral $R 3 \mathrm{c}$ phase (red lines) and the tetragonal $P 4 \mathrm{~mm}$ phase (blue lines).

The compositional range of coexistence of the rhombohedral and the tetragonal structural phases (MPB) in the $\mathrm{BiFeO}_{3}-\mathrm{BiZn}_{0.5} \mathrm{Ti}_{0.5} \mathrm{O}_{3}$ system is essentially broader than that 
observed in the $\mathrm{BiMg}_{0.5} \mathrm{Ti}_{0.5} \mathrm{O}_{3}-\mathrm{BiZn}_{0.5} \mathrm{Ti}_{0.5} \mathrm{O}_{3}$ solid solutions [32], in which the bismuth magnesium titanate is a structural analogue of $\mathrm{PbZrO}_{3}$ [33]. In the latter system, a coexistence of the perovskite phases was observed in the compositional range narrower than 5 at.\%. A wide-range coexistence of the perovskite phases is very typical of the compositions derived from bismuth ferrite since the energy landscape of $\mathrm{BiFeO}_{3}$ is rather flat [34].

The crystal structure refinement was successful considering the two perovskite phases in the as-prepared the $\mathrm{BiFe}_{1-y}\left[\mathrm{Zn}_{0.5} \mathrm{Ti}_{0.5}\right]_{y} \mathrm{O}_{3}$ samples, namely the rhombohedral $R 3 c$ and the tetragonal $\mathrm{P} 4 \mathrm{~mm}$, which correspond to the structural types of the end members, $\mathrm{BiFeO}_{3}$ and $\mathrm{BiZn}_{0.5} \mathrm{Ti}_{0.5} \mathrm{O}_{3}$, respectively.

The compositional variations of the primitive perovskite unit-cell parameters $\left(a_{p}\right.$, $c_{p}$, and $\left.\alpha_{p}\right)$ and the normalized unit-cell volume $\left(V_{p}=V / Z\right)$ are shown in Figure 2 . The parameters were calculated from the refinement data using the relations for the basis vectors of the rhombohedral $R 3 c$ structure and the parent cubic cell [28]. One can see no significant increment of any of the parameters with $y$ over the whole range. The maximum relative variations were observed for the $c_{p}$ value $\left(\sim 0.6 \%\right.$, the $P 4 \mathrm{~mm}$ phase) and the $V_{p}$ value ( 1.4\%, $R 3 c$ phase). As a result, the difference between the normalized unit-cell values of the phases is almost constant over their coexistence range (Figure $2 b$ ).
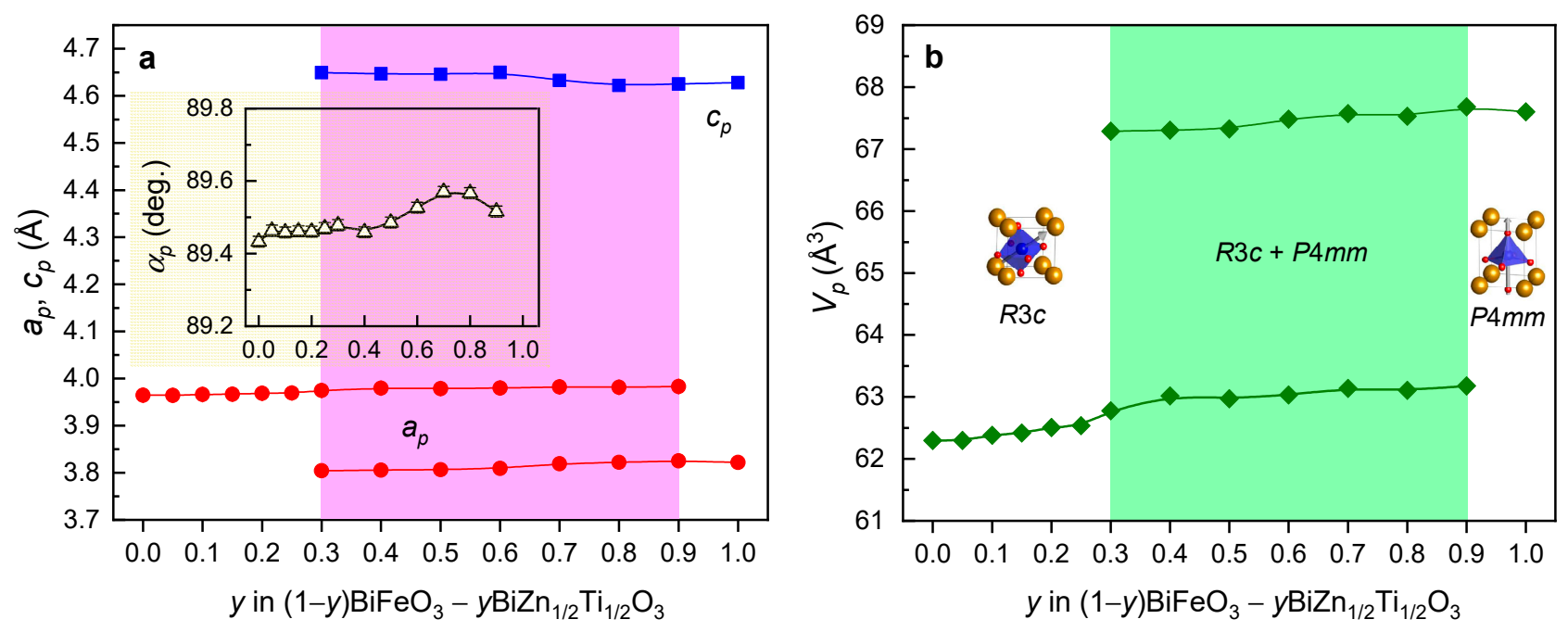

Figure 2. (a) The primitive perovskite cell parameters and (b) the normalized unit-cell volume of the $\mathrm{BiFe}_{1-y}\left[\mathrm{Zn}_{0.5} \mathrm{Ti}_{0.5}\right]_{y} \mathrm{O}_{3}$ perovskite phases as a function of $y$ with the ranges of phase coexistence $(0.30 \leq y \leq 0.90)$ indicated. The data for the end members ( $y=0$ and $y=1)$ were taken from Refs. [31,35], respectively. The polyhedral representations of the respective structures are shown.

The most representative results of magnetic measurements of the $\mathrm{BiFe}_{1-y}\left[\mathrm{Zn}_{0.5} \mathrm{Ti}_{0.5}\right]_{y} \mathrm{O}_{3}$ samples are shown in Figures 3 and 4. It was earlier found [28] that the Néel temperature is more pronounced in magnetic data for the heat-treated samples. Therefore, the annealed samples were used for the estimation of the $T_{\mathrm{N}}$ values. The temperature dependence of the magnetic moment measured in the field-cooled (FC) regime in an applied magnetic field of 500 Oe from the temperature high enough above the transition temperature down to $330 \mathrm{~K}$ is shown in Figure 3. 


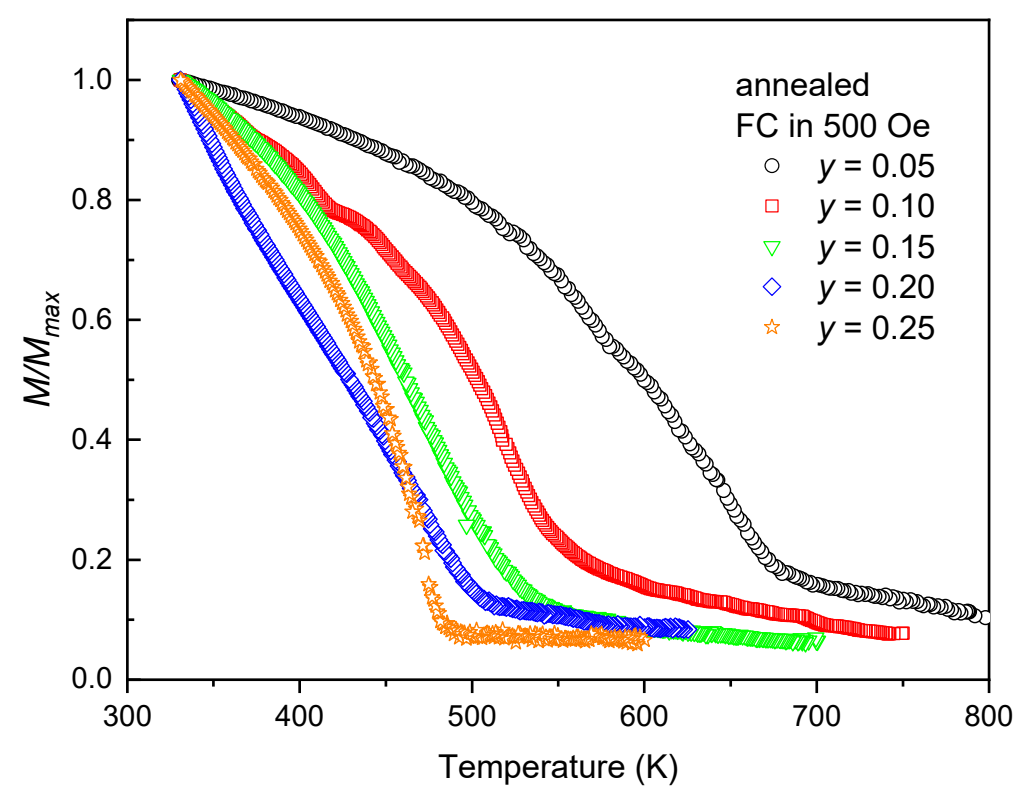

Figure 3. The normalized temperature-dependent magnetic moment of the annealed $\mathrm{BiFe}_{1-y}\left[\mathrm{Zn}_{0.5} \mathrm{Ti}_{0.5}\right]_{y} \mathrm{O}_{3}$ samples measured in the $\mathrm{FC}$ regime in the temperature range above $330 \mathrm{~K}$.

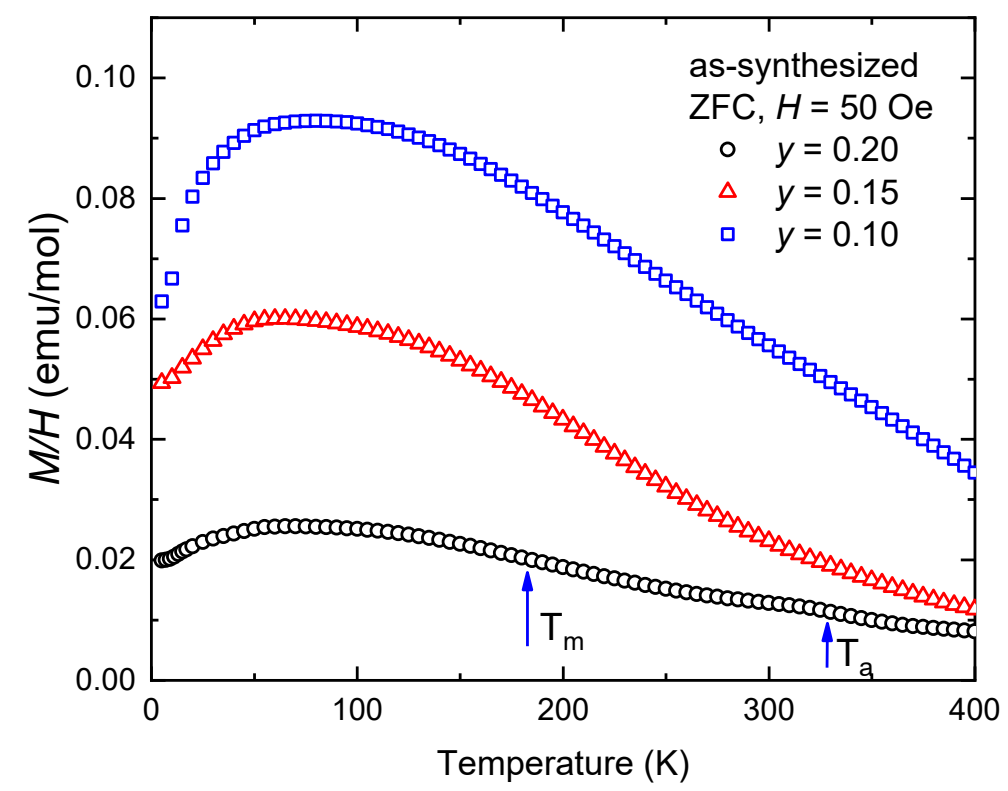

Figure 4. Temperature dependence of $M / H$ of the as-synthesized $\mathrm{BiFe}_{1-y}\left[\mathrm{Zn}_{0.5} \mathrm{Ti}_{0.5}\right]_{y} \mathrm{O}_{3}$ samples with $0.1 \leq y<0.2$ measured in the ZFC regime in the temperature range of $5-400 \mathrm{~K}$. The $T_{m}$ and $T_{a}$ were estimated from the derivative of the $M / H(T)$ curve.

Two anomalies in the temperature-dependent magnetic moment considered as indications of magnetic transformations (assigned as $T_{m}$ and $T_{a}$ ) were observed in the AFM state of the $\mathrm{BiFe}_{1-y} \mathrm{Sc}_{y} \mathrm{O}_{3}$ ceramics in the compositional range of $0.1 \leq y<0.25$ [26]. The signature of similar behaviour was also observed in the $\mathrm{BiFe}_{1-y}\left[\mathrm{Zn}_{0.5} \mathrm{Ti}_{0.5}\right]_{y} \mathrm{O}_{3}$ phase with $y=0.25$ [28]. Therefore, the low-temperature magnetic moment of $\mathrm{BiFe}_{1-y}\left[\mathrm{Zn}_{0.5} \mathrm{Ti}_{0.5}\right]_{y} \mathrm{O}_{3}$ with $0.1 \leq y<0.2$ was measured in the temperature range of $5-400 \mathrm{~K}$ in a small applied field of 50 Oe. Similar behaviour was observed for as-synthesized and annealed samples. As can be seen from the data measured using as-synthesized samples in zero-field-cooled (ZFC) regime in Figure 4, for low $y$ values, there is no clear signature of the transformations as mentioned above in contrast to $\mathrm{BiFe}_{1-y} \mathrm{Sc}_{y} \mathrm{O}_{3}$ [26]. Possible transformations of the magnetic 
structure shown by arrows in Figure 4 were revealed for $y=0.2$ only from the derivative of the $M / H(T)$ curve.

An interesting behaviour was observed in the magnetization loops. The shape of the magnetization loops of the as-synthesized $\mathrm{BiFe}_{1-y}\left[\mathrm{Zn}_{0.5} \mathrm{Ti}_{0.5}\right]_{y} \mathrm{O}_{3}$ samples resembles those of $\mathrm{BiFe}_{1-y} \mathrm{Sc}_{y} \mathrm{O}_{3}$ [26], which can be described as a superposition of linear AFM and hysteretic FM contribution. The annealing leads to an increase in coercivity, remnant magnetization, and the total magnetization at the maximum applied field. Example data are depicted for $y=0.15$ in the inset of Figure 5 with $H_{C}=1.43 \mathrm{kOe}$ and $H_{C}=4.63 \mathrm{kOe}$ for the as-synthesized and the annealed sample, respectively. The observed change in the shape of the magnetization loops after the annealing is of particular interest. The magnetization loops clearly indicate the presence of metamagnetic behaviour particularly pronounced in the compositions with $y=0.05$ and $y=0.1$. Apparently, the magnetic state of the studied samples is nonhomogeneous, and they consist of at least two phases. One of them is weak ferromagnet (i.e., canted antiferromagnet), and another is either a modulated cycloid, similar to the undoped $\mathrm{BiFeO}_{3}$, or collinear antiferromagnet (no spin canting) as in the ground state of polar $\mathrm{BiFe}_{0.7} \mathrm{Sc}_{0.3} \mathrm{O}_{3}$ [23]. The metamagnetic behaviour can be attributed to the latter phase, where the magnetic field switches the spin ordering from the modulated to collinear. The field-induced transition is reversible at room temperature resulting in the unusual shape of the magnetization loops. It has to be pointed out that such transition is also well-known in $\mathrm{BiFeO}_{3}$ [36,37], however, with the critical field significantly higher than in the present case. The phase fraction of the modulated/collinear metamagnetic phase decreases with $y$, and it vanishes in the compositions with $y \geq 0.2$. These experimental observations can be interpreted as a composition-induced first-order phase transition with an extremely large phase coexisting region. In this scenario, the hysteretic region might also depend on temperature, resulting in a very complex composition-temperature-field phase diagram. On the other hand, the weak ferromagnet phase itself can exhibit metamagnetic re-orientation of the magnetic moments at low magnetic fields, as reported in the case of high-pressure synthesized $\mathrm{BiFe}_{0.75} \mathrm{Mn}_{0.25} \mathrm{O}_{3}$ [22].

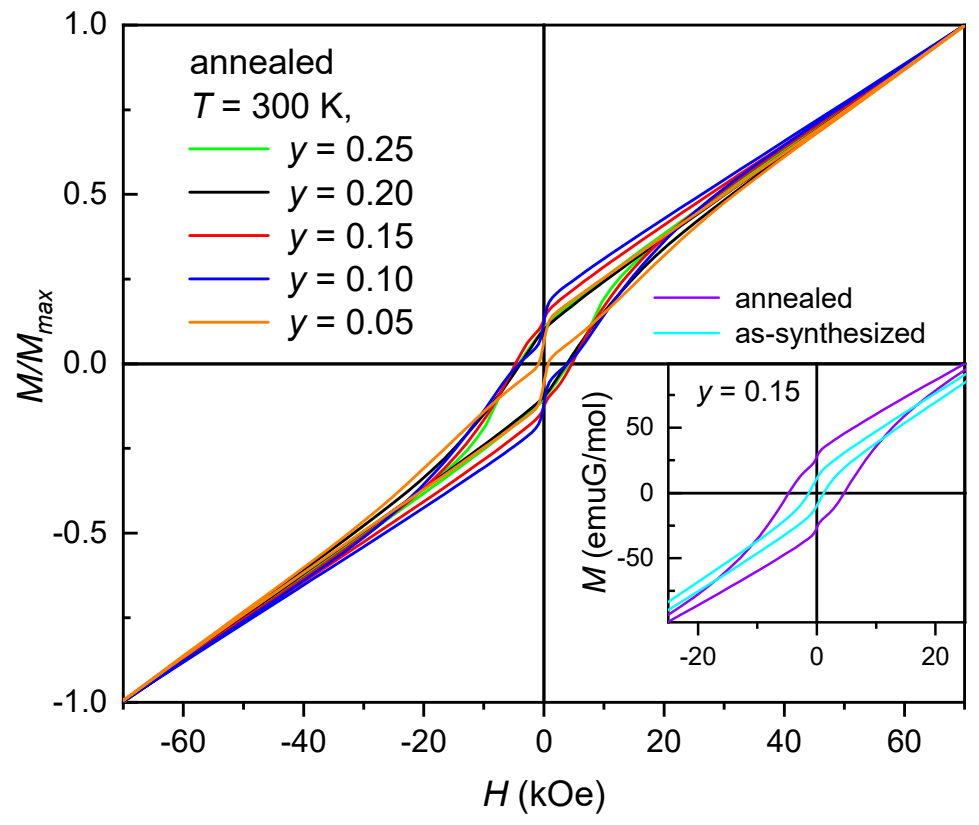

Figure 5. Magnetization loops of the annealed $\mathrm{BiFe}_{1-y}\left[\mathrm{Zn}_{0.5} \mathrm{Ti}_{0.5}\right]_{y} \mathrm{O}_{3}$ samples measured at $300 \mathrm{~K}$ normalized to the magnetization value $M_{\max }$ at the maximum applied field. The inset shows the magnetization loop for the composition with $y=0.15$ before and after annealing.

\section{Discussion}

It follows from the available data on the bulk perovskite $\mathrm{BiFe}_{1-y} B^{3+}{ }_{y} \mathrm{O}_{3}$ solid solutions that the $\mathrm{BiFeO}_{3}$-type rhombohedral phase remains in the compositions with up to about 
30 at.\% substitution rate regardless of the preparation method. In particular, the $R 3 c$ range is $y \leq 0.3$ for Ga [16], $y \leq 0.25$ for Co [14], $y \leq 0.30$ for Mn [12], $y \leq 0.25$ for Sc [19], and $y \leq 0.30$ for $\mathrm{Zn}_{0.5} \mathrm{Ti}_{0.5}$ (see Results). The only known exception is the iron-to-chromium substitution, at which $\mathrm{BiFe}_{0.50} \mathrm{Cr}_{0.50} \mathrm{O}_{3}$ is still rhombohedral [13,20]. In the cases when the perovskite $\mathrm{BiFe}_{1-y} B^{3+}{ }_{y} \mathrm{O}_{3}$ phase is prepared via high-pressure synthesis, annealing may extend (by about 5 at.\%) the compositional range of the rhombohedral structure [22,23].

Figure 6 shows the value of the normalized unit-cell volume for the $\mathrm{BiFe}_{1-y} B^{3+}{ }_{y} \mathrm{O}_{3}$ perovskites as a function of $y$ in the range of their $R 3 c$ phase. The $V_{p}(y)$ dependences in this range are roughly linear with the slopes, which correlate well with the ionic radii of these $B^{3+}$ cations in octahedral coordination.

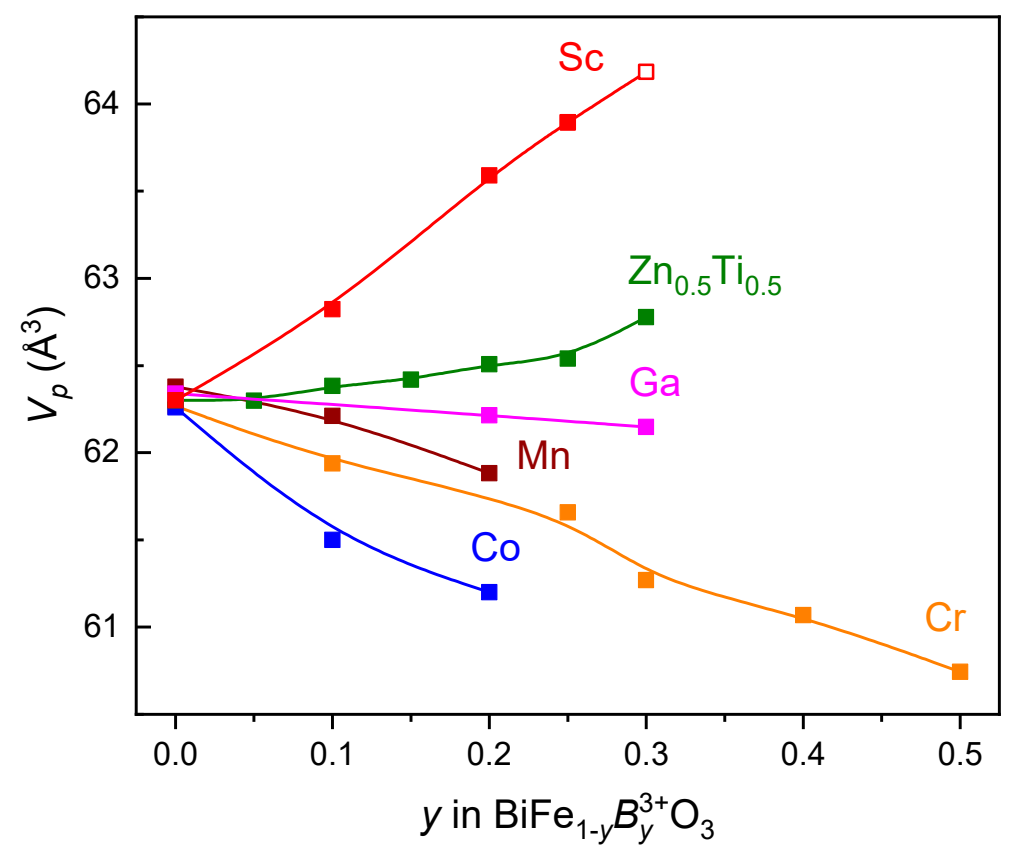

Figure 6. The compositional behaviour of the normalized unit-cell volume for the $\mathrm{BiFe}_{1-y} B^{3+}{ }_{y} \mathrm{O}_{3}$ perovskites with $B^{3+}=\mathrm{Ga}$ [16], Co [14], Mn [11], Cr [20], Sc [19], and $\mathrm{Zn}_{0.5} \mathrm{Ti}_{0.5}$ (this work). The data corresponding to the rhombohedral $R 3 c$ phase range are only shown. The $V_{p}$ value of the $\mathrm{BiFe}_{0.70} \mathrm{Sc}_{0.30} \mathrm{O}_{3}$ perovskite (open symbol) was determined by refinement of neutron diffraction data collected at room temperature on the annealed sample with the $R 3 c$ symmetry (see Ref. [23] for details).

In the $\mathrm{BiFe}_{1-y} \mathrm{~B}^{3+}{ }_{y} \mathrm{O}_{3}$ systems, in which iron is substituted by $\mathrm{Mn}, \mathrm{Cr}$, or $\mathrm{Sc}$, the rhombohedral $R 3 c$ phase borders with the antipolar orthorhombic Pnma phase $[12,19,20]$. When the substituting element is $\mathrm{Co}$ or $\mathrm{Ga}$, the $R 3 c$ phase is followed by the monoclinic $\mathrm{Cm}$ one $[14,16]$. According to results reported by Pan et al. [18], increasing $y$ in the annealed $(1-y) \mathrm{BiFeO}_{3}-y \mathrm{BiZn}_{0.5} \mathrm{Ti}_{0.5} \mathrm{O}_{3}$ ceramics leads to a crossover from the rhombohedral to the monoclinic $C c$ structure, while the data obtained in this work indicate that the next perovskite phase in the ceramics as-synthesized under high-pressure is the tetragonal $P 4 \mathrm{~mm}$.

Generally, the structure sequence (starting from the rhombohedral one at $y=0$ ) in the $\mathrm{BiFe}_{1-y} B^{3+}{ }_{y} \mathrm{O}_{3}$ perovskites is determined by the structural type of the $\mathrm{BiB}^{3+} \mathrm{O}_{3}$ end member. In particular, in spite of the considerable size difference in the $B^{3+}$ cations, the as-synthesized metastable perovskites $\mathrm{BiMnO}_{3}, \mathrm{BiCrO}_{3}$, and $\mathrm{BiScO}_{3}$ all are monoclinic $\mathrm{C} 2 / c$ [35]. As a result, the sequence of the structural phases in the $\mathrm{BiFeO}_{3}$ derived solid solutions with these perovskites is the same, namely $R 3 c-P n m a-C 2 / c$ as $y$ is increased. Analogously, in the solid solutions with $\mathrm{BiCoO}_{3}$ and $\mathrm{BiZn}_{0.5} \mathrm{Ti}_{0.5} \mathrm{O}_{3}$, which are both tetragonal P4mm [31,38], the sequence is $R 3 c-C m$ (or $C c$ ) $-P 4 m m$. The crystal structure of $\mathrm{BiGaO}_{3}$ is of a pyroxene-type [16]. Therefore, the structure sequence observed in the $\mathrm{BiFe}_{1-y} \mathrm{Ga}_{y} \mathrm{O}_{3}$ series is essentially different from the aforementioned ones. 
The $\mathrm{BiFe}_{1-y} B^{3+}{ }_{y} \mathrm{O}_{3}$ perovskites are all antiferromagnets, at least in the range of the rhombohedral phase. Their $T_{\mathrm{N}}$ values are shown in Figure 7 as functions of the substitution rate. One can see that regardless of the nature of the substituting $B^{3+}$ cation, the Néel temperature decreases with $y$. Moreover, the negative increment, $\Delta T_{N} / \Delta y$ is roughly the same for the solid solutions, in which $B^{3+}=\mathrm{Mn}, \mathrm{Cr}$, Sc, and $\mathrm{Zn}_{0.5} \mathrm{Ti}_{0.5}$ (as obtained in this work from Figure 3). To the best of our knowledge, no data on the $T_{N}(y)$ dependence has been reported regarding the iron-to-cobalt substitution. Taking into account the $T_{\mathrm{N}}(y)$ behaviour for the systems with manganese and chromium, a possible compositional variation of the Néel temperature for the (1-y) $\mathrm{BiFeO}_{3}-y \mathrm{BiCoO}_{3}$ system has been suggested (dashed line in Figure 7). Surprisingly, in the case of the iron-to-scandium substitution [26], magnetic ordering still remains at $y=0.60$.

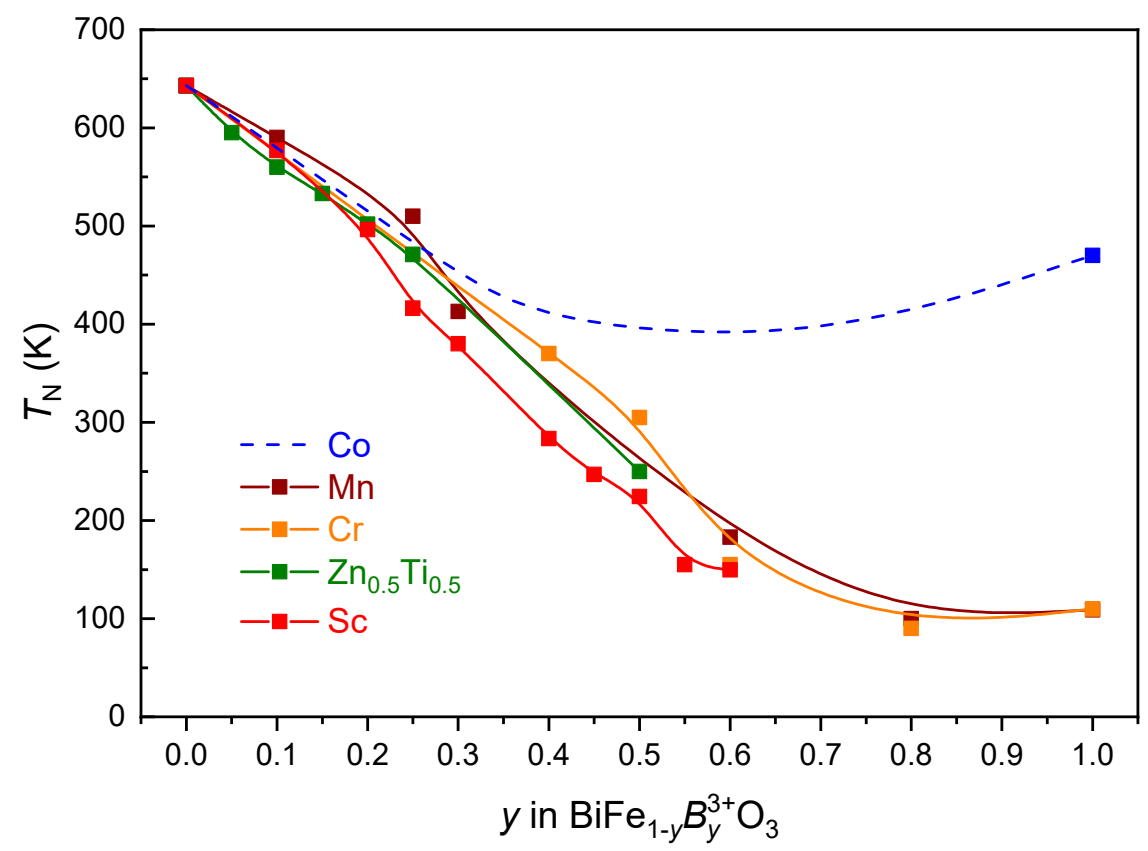

Figure 7. The Néel temperature as a function of $y$ for the $\mathrm{BiFe}_{1-y} B^{3+}{ }_{y} \mathrm{O}_{3}$ perovskites with $B^{3+}=$ Co [39], Mn [12], Cr [29], Sc [26] and $\mathrm{Zn}_{0.5} \mathrm{Ti}_{0.5}$ (this work). A suggested $T_{\mathrm{N}}(y)$ behaviour for the $(1-y) \mathrm{BiFeO}_{3}-y \mathrm{BiCoO}_{3}$ perovskites is shown with the dashed line.

In the annealed samples of the $\mathrm{BiFe}_{1-y} \mathrm{Sc}_{y} \mathrm{O}_{3}$ series with $y=0.30$, a reversible transition between the AFM state with the cycloidal incommensurate modulation and the collinear AFM ground state was observed at $T_{\mathrm{m}}=230 \mathrm{~K}$ [23]. The as-synthesized $\mathrm{BiFe}_{0.70} \mathrm{Sc}_{0.30} \mathrm{O}_{3}$ phase is the orthorhombic Pnma, while the annealed polymorph of this composition is the rhombohedral R3c. No such AFM-AFM transition has been detected in the asprepared material [23]. That is why it was suggested that conversion polymorphysm is responsible for the formation of the collinear AFM ground state in $\mathrm{BiFe}_{0.7} \mathrm{Sc}_{0.3} \mathrm{O}_{3}$. However, Rusakov et al. [21] have reported on the reversible transition between the AFM states with the cycloidal and the collinear spin arrangements in the high-pressure stabilized $\mathrm{BiFe}_{0.8} \mathrm{Cr}_{0.2} \mathrm{O}_{3}$ at $T_{m}=260 \mathrm{~K}$. This composition demonstrates no conversion polymorphism and is rhombohedral before and after annealing. Therefore, the formation of the AFM states different from the modulated cycloidal one can be rather associated with the features caused by the high-pressure synthesis of the aforementioned perovskites.

In addition to the transition at $T_{m}$, the magnetic measurements of the $\mathrm{BiFe}_{1-y} \mathrm{Sc}_{y} \mathrm{O}_{3}$ samples with compositions $0.10 \leq y \leq 0.30$ revealed some anomalies in the $M(T)$ dependences at $T_{a}\left(T_{m}<T_{a}<T_{\mathrm{N}}\right)$ that were also associated with the transitions between different AFM states [26]. As seen from Figure 4, no clear evidence of the AFM-AFM phase transformation (at $T_{m}$ and /or $T_{a}$ ) in $\mathrm{BiFe}_{1-y}\left[\mathrm{Zn}_{0.5} \mathrm{Ti}_{0.5}\right]_{y} \mathrm{O}_{3}$ can be found for the compositions with $y<0.20$, which may point to the differences in the lattice distortions induced by the 
substituting atoms of different sizes. Relatively large scandium (with the C.N. 6 ionic radius of $0.89 \AA$ versus $0.69 \AA$ for iron) may cause significant destruction of cycloidal spin arrangement in the parent $\mathrm{BiFeO}_{3}$ at much lower substitution levels as for $B^{3+}=\mathrm{Cr}$ and $\mathrm{Zn}_{0.5} \mathrm{Ti}_{0.5}$ that are similar in size to $\mathrm{Fe}^{3+}$.

A substitution usually induces short-range (deformation of $\mathrm{Fe}^{3+}$ coordination octahedra) and long-range structural distortions with the $\mathrm{Fe}^{3+}-\mathrm{O}^{2-}-\mathrm{Fe}^{3+}$ bond angle change. This may lead to the change in magnetic exchange and the spin canting due to the induced DM interaction, thus enhancing the FM component of the magnetization $[10,40,41]$, as seen in Figure 5. On the other hand, the bismuth site substitution can also cause FM contribution originating from the created oxygen vacancies due to charge compensation achieved by oxygen deficiency after introducing alkali earth ions (e.g., $\mathrm{Ca}^{2+}$ ) in the $\mathrm{BiFeO}_{3}$ crystal structure [42]. An enhancement of ferromagnetism in $\mathrm{BiFeO}_{3}$ can also be achieved by reducing crystallite size into the nanometre scale when the size becomes comparable with the AFM cycloid period of $\sim 62 \mathrm{~nm}[43,44]$. However, the FM contribution may be enhanced by mechanically induced distortions even in larger $\mathrm{BiFeO}_{3}$ crystallites [45] (as revealed from significant hysteresis in the magnetization loops similar to those shown in Figure 5) when the material is prepared using the mechanochemical synthesis. Such an observation would point to the critical role of the high-pressure synthesis procedure of $\mathrm{BiFe}_{1-y} B^{3+}{ }_{y} \mathrm{O}_{3}$ perovskite solid solutions introducing mechanical strain and affecting the magnitude of uncompensated magnetic moments in initial cycloidal AFM arrangement. The enhancement of the ferromagnetism and possible spin canting, suggested from the observed shape of the hysteresis loops in Figure 5, may not be solely the result of chemically induced distortions of the iron substitution but a combined effect.

The dependence of the Néel temperature on the $B^{3+}$ substitution rate in $\mathrm{BiFe}_{1-y} B^{3+}{ }_{y} \mathrm{O}_{3}$ perovskites shown in Figure 7 obviously follows the same trend for different types of iron substitution. Presented results also suggest that the phenomenon of reversible transitions between magnetic states with different types of AFM ordering (collinear, canted, and cycloidal spin arrangements) shares the same features and deserves a particular study. It is very likely that this phenomenon is rather general and was overlooked in the systems with $B^{3+}=\mathrm{Co}$ and Ga.

\section{Materials and Methods}

Ceramics of the $\mathrm{BiFe}_{1-y}\left[\mathrm{Zn}_{0.5} \mathrm{Ti}_{0.5}\right]_{y} \mathrm{O}_{3}$ series $(0.05 \leq y \leq 0.90)$ were synthesized under high pressure from the precursors prepared via a solid-state reaction from the stoichiometric oxide mixtures. Details of the precursor preparation and the high-pressure synthesis can be found in Ref. [28].

Phase analysis of the samples before and after annealing was performed using a PANalytical X'Pert Powder X-ray diffractometer (XRD, Ni-filtered $\mathrm{Cu} K \alpha$ radiation) at room temperature. Before the XRD measurements, the samples were reduced into powders. The crystal structure and the magnetic structure of the samples were refined using the FULLPROF package [46].

Magnetic properties of the ceramic samples were measured in the range of 5-300 K using a commercial Quantum Design MPMS3 magnetometer in applied fields up to $70 \mathrm{kOe}$ in both ZFC and FC regimes. For the ZFC measurements, the samples were heated to $400 \mathrm{~K}$, demagnetized from the applied field of $10 \mathrm{kOe}$ to zero field in the Oscillate Mode, and the residual field was removed by the built-in Magnet Reset quench procedure. High temperature (over the range of 300-800 K) measurements were done using a commercial Quantum Design MPMS-XL5 magnetometer equipped with an oven insert. Some of the ceramic samples were annealed prior to the magnetic measurements. Annealings were done in air at $720 \mathrm{~K}$ for $1 \mathrm{~h}$.

\section{Conclusions}

In the as-synthesized (unannealed) ceramics of the $\mathrm{BiFe}_{1-y}\left[\mathrm{Zn}_{0.5} \mathrm{Ti}_{0.5}\right]_{y} \mathrm{O}_{3}$ series $(0.05$ $\leq y \leq 0.90)$ prepared using high-pressure synthesis, two perovskite crystalline phases 
were detected, namely the rhombohedral $R 3 \mathrm{c}$, which is similar to that in the parent $\mathrm{BiFeO}_{3}$, and the tetragonal P4mm as that in the high-pressure stabilized $B i \mathrm{Zn}_{0.5} \mathrm{Ti}_{0.5} \mathrm{O}_{3}$. No other crystalline phases have been revealed in the obtained samples. The rhombohedral and the tetragonal phases coexist in a wide compositional range (morphotropic phase region) of $0.30 \leq y \leq 0.90$. In this region, the relative difference between the normalized unit-cell values $\left(V_{p}\right)$ of the phases is almost constant, $\Delta V_{p} / V_{p} \approx 7 \%$.

The magnetic behaviour of the $\mathrm{BiFe}_{1-y}\left[\mathrm{Zn}_{0.5} \mathrm{Ti}_{0.5}\right]_{y} \mathrm{O}_{3}$ solid solutions with $y<0.30$ is typical of antiferromagnets whose Néel temperature $\left(T_{N}\right)$ linearly decreases with $y$. Ferromagnetic contribution to their magnetic moment was revealed. This contribution was found to be more substantial in the annealed samples.

The $V_{p}(y)$ dependences of the $\mathrm{BiFe}_{1-y} B^{3+}{ }_{y} \mathrm{O}_{3}$ perovskites $\left(B^{3+}=\mathrm{Ga}, \mathrm{Co}, \mathrm{Mn}, \mathrm{Cr}\right.$, Sc, and $\left.\mathrm{Zn}_{0.5} \mathrm{Ti}_{0.5}\right)$ in the compositional range of their rhombohedral phase are approximately linear with the slopes, which correlate well with the ionic radii of these $B^{3+}$ cations in octahedral coordination. In particular, the biggest positive slope and the biggest negative slope are observed in the series with $B^{3+}=C o$ and Sc, respectively.

In contrast to the $B^{3+}$ ionic size dependent $V_{p}(y)$ behaviours of the $\mathrm{BiFe}_{1-y} B^{3+}{ }_{y} \mathrm{O}_{3}$ perovskites, the compositional dependences of the Néel temperature in the range of their rhombohedral crystalline phases are essentially similar regardless of the nature (magnetic or non-magnetic) of the $B^{3+}$ cation.

The anomalies in the temperature behaviour of the magnetic moment below $T_{\mathrm{N}} \mathrm{ob}-$ served in the $\mathrm{BiFe}_{1-y} B^{3+}{ }_{y} \mathrm{O}_{3}$ perovskites with $B^{3+}=\mathrm{Cr}, \mathrm{Sc}$, and $\mathrm{Zn}_{0.5} \mathrm{Ti}_{0.5}$ are assumed to indicate to the reversible transitions between magnetic states with different types of antiferromagnetic ordering (collinear, canted, and cycloidal spin arrangements). Occurrence of such transitions is likely to be characteristic of the high-pressure stabilized nature of the $\mathrm{BiFe}_{1-y} B^{3+}{ }_{y} \mathrm{O}_{3}$ perovskites and deserves a particular study.

Author Contributions: Conceptualization, A.N.S., V.V.S., D.D.K., and E.Č.; data curation, E.L.F., A.V.F., E.Č., R.T., Y.V.R., A.V.P., and J.P.V.C.; formal analysis, E.Č., R.T. and J.P.V.C.; investigation, E.Č., Y.V.R., A.V.P., J.P.V.C., and A.N.S.; methodology, D.D.K. and A.N.S.; project administration, E.Č. and N.M.O.; resources, A.F. and J.M.V.; supervision, A.F., and J.M.V.; validation, N.M.O. and J.M.V.; visualization, E.Č., J.P.V.C., and A.N.S.; writing—original draft, A.N.S.; writing—review and editing, E.Č., D.D.K., V.V.S., A.F., J.M.V., and A.N.S. All authors have read and agreed to the published version of the manuscript.

Funding: This work was done in the frame of the bilateral Slovakia-Belarus project APVV SKBY-RD-19-0008/T20SLKG-001 funded by the Slovak Research and Development Agency and the Belarusian Republican Foundation for Fundamental Research, respectively. J.P.V.C acknowledges the financial support of FCT-the Portuguese Foundation for Science and Technology for the Ph.D. grant SFRH/BD/145281/2019. A.N.S. acknowledges the financial support of national funds (OE) through FCT-Portugal in the scope of the framework contract foreseen in the numbers 4,5 , and 6 of the article 23, of the Decree-Law 57/2016, of 29 August, changed by Law 57/2017, of 19 July. The research done in University of Aveiro was supported by the project CICECO-Aveiro Institute of Materials, UIDB/50011/2020 and UIDP/50011/2020, financed by national funds through the Portuguese Foundation for Science and Technology (FCT)/MCTES.

Conflicts of Interest: The authors declare no conflict of interest.

\section{References}

1. Khomskii, D. Classifying multiferroics: Mechanisms and effects. Physics 2009, 2, 20. [CrossRef]

2. Catalan, G.; Scott, J.F. Physics and applications of bismuth ferrite. Adv. Mater. 2009, 21, 2463-2485. [CrossRef]

3. Pyatakov, A.P.; Zvezdin, A.K. Magnetoelectric and multiferroic media. Phys.-Uspekhi 2012, 55, 557-581. [CrossRef]

4. Sosnowska, I.; Peterlin-Neumaier, T.; Steichele, E. Spiral magnetic ordering in bismuth ferrite. J. Phys. C Solid State Phys. 1982, 15, 4835-4846. [CrossRef]

5. Arnold, D.C. Composition-driven structural phase transitions in rare-earth-doped $\mathrm{BiFeO}_{3}$ ceramics: A review. IEEE Trans. Ultrason. Ferroelectr. Freq. Control. 2015, 62, 62-82. [CrossRef]

6. Song, G.; Song, Y.; Su, J.; Song, X.; Zhang, N.; Wang, T.; Chang, F. Crystal structure refinement, ferroelectric and ferromagnetic properties of $\mathrm{Ho}^{3+}$ modified $\mathrm{BiFeO}_{3}$ multiferroic material. J. Alloys Compd. 2017, 696, 503-509. [CrossRef] 
7. Gebhardt, J.; Rappe, A.M. Doping of $\mathrm{BiFeO}_{3}$ : A comprehensive study on substitutional doping. Phys. Rev. B 2018, $98,125202$. [CrossRef]

8. Surdu, V.A.; Truşcă, R.; Vasile, B.S.; Oprea, O.; Tanasa, E.; Diamandescu, L.; Andronescu, E.; Ianculescu, A. Bi $\mathrm{Bi}_{1-\mathrm{x}} \mathrm{Eu}_{\mathrm{x}} \mathrm{FeO} \mathrm{O}_{3}$ powders: Synthesis, characterization, magnetic and photoluminescence properties. Nanomaterials 2019, 9, 1465. [CrossRef] [PubMed]

9. Mumtaza, F.; Nasira, S.; Hassnain Jaffaria, G.; Ismat Shah, S. Chemical pressure exerted by rare earth substitution in BiFeO ${ }_{3}$ : Effect on crystal symmetry, band structure and magnetism. J. Alloys Compd. 2021, 876, 160178. [CrossRef]

10. Yang, C.-H.; Kan, D.; Takeuchi, I.; Nagarajan, V.; Seidel, J. Doping $\mathrm{BiFeO}_{3}$ : Approaches and enhanced functionality. Phys. Chem. Chem. Phys. 2012, 14, 15953-15962. [CrossRef]

11. Sosnowska, I.; Schäfer, W.; Kockelmann, W.; Andersen, K.H.; Troyanchuk, I.O. Crystal structure and spiral magnetic ordering of BiFeO3 doped with manganese. Appl. Phys. A 2002, 74, s1040-s1042. [CrossRef]

12. Azuma, M.; Kanda, H.; Belik, A.A.; Shimakawa, Y.; Takano, M. Magnetic and structural properties of $\mathrm{BiFe}_{1-\mathrm{x}} \mathrm{Mn}_{\mathrm{x}} \mathrm{O}_{3}$. J. Magn . Magn. Mater. 2007, 310, 1177-1179. [CrossRef]

13. Suchomel, M.R.; Thomas, C.I.; Allix, M.; Rosseinsky, M.J.; Fogg, A.M.; Thomas, M.F. High pressure bulk synthesis and characterization of the predicted multiferroic $\mathrm{Bi}\left(\mathrm{Fe}_{1 / 2} \mathrm{Cr}_{1 / 2}\right) \mathrm{O}_{3}$. Appl. Phys. Lett. 2007, 90, 112909. [CrossRef]

14. Azuma, M.; Niitaka, S.; Hayashi, N.; Oka, K.; Takano, M.; Funakubo, H.; Shimakawa, Y. Rhombohedral-tetragonal phase boundary with high Curie temperature in (1-x) $\mathrm{BiCoO}_{3-\mathrm{x}} \mathrm{BiFeO}_{3}$ solid solution. Jpn. J. Appl. Phys. 2008, 47, 7579-7581. [CrossRef]

15. Oka, K.; Koyama, T.; Ozaaki, T.; Mori, S.; Shimakawa, Y.; Azuma, M. Polarization rotation in the monoclinic perovskite $\mathrm{BiCo}_{1-\mathrm{x}} \mathrm{Fe}_{\mathrm{x}} \mathrm{O}_{3}$. Angew. Chem. Int. Ed. 2012, 51, 7977-7980. [CrossRef]

16. Belik, A.A.; Rusakov, D.A.; Furubayashi, T.; Takayama-Muromachi, E. $\mathrm{BiGaO}_{3}$-based perovskites: A large family of polar materials. Chem. Mater. 2012, 24, 3056-3064. [CrossRef]

17. Khalyavin, D.D.; Salak, A.N.; Olekhnovich, N.M.; Pushkarev, A.V.; Radyush, Y.V.; Manuel, P.; Raevski, I.P.; Zheludkevich, M.L.; Ferreira, M.G.S. Polar and antipolar polymorphs of metastable perovskite $\mathrm{BiFe}_{0.5} \mathrm{Sc}_{0.5} \mathrm{O}_{3}$. Phys. Rev. B 2014, 89, 174414. [CrossRef]

18. Pan, Z.; Chen, J.; Yu, R.; Yamamoto, H.; Rong, Y.; Hu, L.; Li, Q.; Lin, K.; You, L.; Zhao, K.; et al. Giant polarization and high temperature monoclinic phase in a lead-free perovskite of $\mathrm{Bi}\left(\mathrm{Zn}_{0.5} \mathrm{Ti}_{0.5}\right) \mathrm{O}_{3}-\mathrm{BiFeO}_{3}$. Inorg. Chem. 2016, 55, 9513-9516. [CrossRef]

19. Salak, A.N.; Khalyavin, D.D.; Pushkarev, A.V.; Radyush, Y.V.; Olekhnovich, N.M.; Shilin, A.D.; Rubanik, V.V. Phase formation in the (1-y) $\mathrm{BiFeO}_{3}-y \mathrm{BiScO}_{3}$ system under ambient and high pressure. J. Solid State Chem. 2017, 247, 90-96. [CrossRef]

20. Raevski, I.P.; Kubrin, S.P.; Pushkarev, A.V.; Olekhnovich, N.M.; Radyush, Y.V.; Titov, V.V.; Malitskaya, M.A.; Raevskaya, S.I.; Chen, $\mathrm{H}$. The effect of $\mathrm{Cr}$ substitution for Fe on the structure and magnetic properties of $\mathrm{BiFeO}_{3}$ multiferroic. Ferroelectrics 2018, 525, 1-10. [CrossRef]

21. Rusakov, V.S.; Pokatilov, V.S.; Sigov, A.S.; Belik, A.A.; Matsnev, M.E. Changes in the magnetic structure of multiferroic $\mathrm{BiFe}_{0.80} \mathrm{Cr}_{0.20} \mathrm{O}_{3}$ with temperature. Phys. Solid State 2019, 61, 1030-1036. [CrossRef]

22. Belik, A.A.; Abakumov, A.M.; Tsirlin, A.A.; Hadermann, J.; Kim, J.; Van Tandeloo, G.; Takayama-Muromachi, E. Structure and magnetic properties of $\mathrm{BiFe}_{0.75} \mathrm{Mn}_{0.25} \mathrm{O}_{3}$ perovskite prepared at ambient and high pressure. Chem. Mater. 2011, 42, $4505-4514$. [CrossRef]

23. Khalyavin, D.D.; Salak, A.N.; Fertman, E.L.; Kotlyar, O.V.; Eardley, E.; Olekhnovich, N.M.; Pushkarev, A.V.; Radyush, Y.V.; Fedorchenko, A.; Desnenko, V.A.; et al. The phenomenon of conversion polymorphism in Bi-containing metastable perovskites. Chem. Commun. 2019, 55, 4683-4686. [CrossRef]

24. Fedorchenko, A.; Fertman, E.L.; Salak, A.N.; Desnenko, V.A.; Čižmár, E.; Feher, A.; Vaisburd, A.I.; Olekhnovich, N.M.; Pushkarev, A.V.; Radyush, Y.V.; et al. Unusual magnetic properties of the polar orthorhombic $\mathrm{BiFe}_{0.5} \mathrm{Sc}_{0.5} \mathrm{O}_{3}$ perovskite. J. Magn. Magn. Mater. 2018, 465, 328-332. [CrossRef]

25. Fertman, E.L.; Fedorchenko, A.; Desnenko, V.A.; Shvartsman, V.V.; Lupascu, D.C.; Salamon, S.; Wende, H.; Vaisburd, A.I.; Stanulis, A.; Ramanauskas, R.; et al. Exchange bias effect in bulk multiferroic $\mathrm{BiFe}_{0.5} \mathrm{Sc}_{0.5} \mathrm{O}_{3}$. AIP Adv. 2020, 10, 045102. [CrossRef]

26. Fertman, E.L.; Fedorchenko, A.V.; Čižmár, E.; Vorobiov, S.; Feher, A.; Radyush, Y.V.; Pushkarev, A.V.; Olekhnovich, N.M.; Stanulis, A.; Barron, A.R.; et al. Magnetic diagram of the high-pressure stabilized multiferroic perovskites of the $\mathrm{BiFe}_{1-y} \mathrm{Sc}_{y} \mathrm{O}_{3}$ series. Crystals 2020, 10, 950. [CrossRef]

27. Shvartsman, V.V.; Khalyavin, D.D.; Olekhnovich, N.M.; Pushkarev, A.V.; Radyush, Y.V.; Salak, A.N. Spontaneous and induced ferroelectricity in the $\mathrm{BiFe}_{1-x} \mathrm{Sc}_{x} \mathrm{O}_{3}$ perovskite ceramics. Phys. Status Solidi A 2021, 218, 2100173. [CrossRef]

28. Čižmár, E.; Vorobiov, S.; Kliuikov, A.; Radyush, Y.V.; Pushkarev, A.V.; Olekhnovich, N.M.; Cardoso, J.P.; Salak, A.N.; Feher, A. Structural and magnetic phase transitions in the Fe-rich compositional ranges of the multiferroic $\mathrm{BiFe}_{1-x}\left[\mathrm{Zn}_{0.5} \mathrm{Ti}_{0.5}\right]_{x} \mathrm{O}_{3}$ perovskites. Integr. Ferroelectr. 2021. [CrossRef]

29. Arafat, S.S. Structural transition and magnetic properties of high Cr-doped $\mathrm{BiFeO}_{3}$ ceramic. Cerâmica 2020, 66, 114-118. [CrossRef]

30. Salak, A.N.; Shilin, A.D.; Bushinski, M.V.; Olekhnovich, N.M.; Vyshatko, N.P. Structural regularities and dielectric phenomena in the compound series $\mathrm{PbB}^{3+}{ }_{1 / 2} \mathrm{Nb}_{1 / 2} \mathrm{O}_{3}$. Mater. Res. Bull. 2000, 35, 1429-1438. [CrossRef]

31. Suchomel, M.R.; Fogg, A.M.; Allix, M.; Niu, H.; Claridge, J.B.; Rosseinsky, M.J. $\mathrm{B}_{\mathrm{i} 2} \mathrm{ZnTiO}_{6}$ : a lead-free closed-shell polar perovskite with a calculated ionic polarization of $150 \mu \mathrm{C} \mathrm{cm}^{-2}$. Chem. Mater. 2006, 18, 4987-4989. [CrossRef]

32. Salak, A.N.; Shvartsman, V.V.; Cardoso, J.P.; Pushkarev, A.V.; Radyush, Y.V.; Olekhnovich, N.M.; Khalyavin, D.D.; Vieira, J.M.; Čižmár, E.; Feher, A. The orthorhombic-tetragonal morphotropic phase boundary in high-pressure synthesized $\mathrm{BiMg}_{0.5} \mathrm{Ti}_{0.5} \mathrm{O}_{3}-$ $\mathrm{BiZn}_{0.5} \mathrm{Ti}_{0.5} \mathrm{O}_{3}$ perovskite solid solutions. J. Phys. Chem. Solids 2022, 161, 110392. [CrossRef] 
33. Khalyavin, D.D.; Salak, A.N.; Vyshatko, N.P.; Lopes, A.B.; Olekhnovich, N.M.; Pushkarev, A.V.; Maroz, I.I.; Radyush, Y.V. Crystal structure of metastable perovskite $\mathrm{Bi}\left(\mathrm{Mg}_{1 / 2} \mathrm{Ti}_{1 / 2}\right) \mathrm{O}_{3}$ : Bi-based structural analogue of antiferroelectric $\mathrm{PbZrO}_{3}$. Chem. Mater. 2006, 18, 5104-5110. [CrossRef]

34. Prosandeev, S.; Wang, D.; Ren, W.; Íñiguez, J.; Bellaiche, L. Novel nanoscale twinned phases in perovskite oxides. Adv. Funct. Mater. 2013, 23, 234-240. [CrossRef]

35. Kubel, F.; Schmid, H. Structure of a ferroelectric and ferroelastic monodomain crystal of the perovskite BiFeO ${ }_{3}$. Acta Cryst. B 1990, 46, 698-702. [CrossRef]

36. Popov, Y.F.; Zvezdin, A.K.; Vorob'ev, G.P.; Kadomtseva, A.M.; Murashev, V.A.; Rakov, D.N. Linear magnetoelectric effect and phase transitions in bismuth ferrite, $\mathrm{BiFeO}_{3}$. JETP Lett. 1993, 57, 69-73.

37. Ruette, B.; Zvyagin, S.; Pyatakov, A.P.; Bush, A.; Li, J.F.; Belotelov, V.I.; Zvezdin, A.K.; Viehland, D. Magnetic-field-induced phase transition in $\mathrm{BiFeO}_{3}$ observed by high-field electron spin resonance: Cycloidal to homogeneous spin order. Phys. Rev. B. 2004, 69, 064114. [CrossRef]

38. Belik, A.A. Polar and nonpolar phases of $\mathrm{BiMO}_{3}$ : A review. J. Solid State Chem. 2012, 195, 32-40. [CrossRef]

39. Belik, A.A.; Iikubo, S.; Kodama, K.; Igawa, N.; Shamoto, S.; Niitaka, S.; Azuma, M.; Shimakawa, Y.; Takano, M.; Izumi, F.; et al. Neutron powder diffraction study on the crystal and magnetic structures of $\mathrm{BiCoO}_{3}$. Chem. Mater. 2006, 18, 798-803. [CrossRef]

40. Sharma, V.; Ghosh, R.K.; Kuanr, B.K. Investigation of room temperature ferromagnetism in transition metal doped $\mathrm{BiFeO}_{3}$. J. Phys. Condens. Matter 2019, 31, 395802. [CrossRef]

41. Freitas, V.F.; Bonadio, T.G.M.; Dias, G.S.; Protzek, O.A.; Medina, A.N.; Cótica, L.F.; Santos, I.A.; Garcia, D.; Eiras, J.A. On the microscopic mechanism for the stabilization of structural and ferroic states in displacive multiferroics. J. Appl. Phys. 2013, 113, 114105. [CrossRef]

42. Sánchez-De Jesús, F.; Bolarín-Miró, A.M.; Cortés-Escobedo, C.A.; Barba-Pingarrón, A.; Pedro-García, F. Enhanced ferromagnetic and electric properties of multiferroic $\mathrm{BiFeO}_{3}$ by doping with Ca. J. Alloys Compd. 2020, 824, 153944. [CrossRef]

43. Huang, F.; Wang, Z.; Lu, X.; Zhang, J.; Min, K.; Lin, W.; Ti, R.; Xu, T.; He, J.; Yue, C.; et al. Peculiar magnetism of BiFeO 3 nanoparticles with size approaching the period of the spiral spin structure. Sci. Rep. 2013, 3, 2907. [CrossRef]

44. Da Silva, K.L.; Menzel, D.; Feldhoff, A.; Kubel, C.; Bruns, M.; Paesano, A., Jr.; Duvel, A.; Wilkening, M.; Ghafari, M.; Hahn, H.; et al. Mechanosynthesized $\mathrm{BiFeO}_{3}$ nanoparticles with highly reactive surface and enhanced magnetization. J. Phys. Chem. C 2011, 115, 7209-7217. [CrossRef]

45. Da Silva, K.L.; Trautwein, R.S.; Da Silva, R.B.; Fabián, M.; Čižmár, E.; Holub, M.; Skurikhina, O.; Harničárová, M.; Girman, V.; Menzel, D.; et al. Suppression of the cycloidal spin arrangement in $\mathrm{BiFeO}_{3}$ caused by the mechanically induced structural distortion and its effect on magnetism. Front. Matter. 2021. [CrossRef]

46. Rodriguez-Carvajal, J. Recent advances in magnetic structure determination by neutron powder diffraction. Phys. B Phys. Condens. Matter 1993, 192, 55-69. [CrossRef] 